\author{
RESEARCH ARTICLE \\ 10.1029/2018JF004750 \\ Key Points: \\ - We present empirical data \\ constraining delta progradation rates \\ measured at modern river outlets \\ - We obtain a model of the rate \\ compilation that predicts it to within \\ an order of magnitude \\ - Our results can help constrain \\ stratigraphic, analog, and numerical \\ models of deltaic deposition
}

Supporting Information:

- Supporting Information S1

- Supporting Information S2

- Data Set S1

- Data Set S2

- Data Set S3

- Data Set S4

- Figure S1

- Figure S2

- Figure S3

- Figure S4

- Figure S5

- Figure S6

Correspondence to:

T. Aadland,

tore.aadland@uib.no

Citation:

Aadland, T., \& Helland-Hansen, W. (2019). Progradation rates measured at modern river outlets: A first-order constraint on the pace of deltaic deposition. Journal of Geophysical Research: Earth Surface, 124, 347-364. https://doi.org/10.1029/2018JF004750

Received 10 MAY 2018 Accepted 25 JAN 2019 Accepted article online 29 JAN 2019 Published online 6 FEB 2019

(C)2019. American Geophysical Union. All Rights Reserved.

\section{Progradation Rates Measured at Modern River Outlets: A First-Order Constraint on the Pace of Deltaic Deposition}

\author{
Tore Aadland $^{1,2}$ (D) and William Helland-Hansen ${ }^{1}$ \\ ${ }^{1}$ Department of Earth Science, University of Bergen, Bergen, Norway, ${ }^{2}$ Research Centre for Arctic Petroleum \\ Exploration, University of Tromsø, Tromsø, Norway
}

\begin{abstract}
We present a compilation of modern shoreline progradation rates measured close to river outlets entering deltaic coastlines, and we discuss how these observations relate to the overall evolution of both modern and ancient deltaic coastlines. We analyzed Landsat-derived satellite images to identify plan view changes in the subaerial morphology of 331 modern deltaic coastlines. Our rate compilation $\left(\mathrm{km}^{2} /\right.$ year) had a lognormal distribution with parameters $\mu=-1.85$ and $\sigma^{2}=1.01$. We found that the rate data could be predicted to within an order of magnitude by an empirically derived power law using only fluvial water discharge and suspended sediment load as input parameters $\left(r_{\text {pro }}=10^{-2.3} Q_{w}^{0.59} Q_{s}^{0.34}\right)$. We justified this river-centric model of our progradation rates by assuming that delta progradation rates measured close to river outlets were more reflective of fluvial processes than of basinal processes, and preliminary tests supported this assumption. Our rate compilation and empirical model could provide useful constraints to guide stratigraphic analysis of ancient source-to-sink systems and to build analog and numerical models.
\end{abstract}

\section{Introduction}

River deltas are landforms that develop adjacent to water bodies in response to deposition of sediment delivered by fluvial systems. Prograding deltaic shorelines are important geological agents that have played important roles in constructing the sedimentary record. Specifically, progradational deposition contributes significantly more to the stratigraphic record than the transgressive counterpart (Helland-Hansen \& Martinsen, 1996; Ryer, 1977). Delta progradation forms shallow marine sediment bodies that can contain significant sand and are important as subsurface reservoirs for oil, gas, water, and sequestered $\mathrm{CO}_{2}$ (e.g., Struijk \& Green, 1991). Deltaic deposits also record shoreline migration patterns, which are a sensitive indicator of geological processes (Helland-Hansen \& Hampson, 2009; Helland-Hansen \& Martinsen, 1996; Kim et al., 2006; Mahon et al., 2015). Consequently, such deposits are an important source of information for reconstructing geological history. Today, half a billion people live on modern delta plains, primarily due to their flat landscapes, fertile soils, and access to waterways and the sea (Kuenzer \& Renaud, 2012). However, these areas are at risk due to human activity (McGranahan et al., 2007; Szabo et al., 2016). Climate change causes rising sea level and increases the frequency and intensity of storms (Knutson et al., 2010; Webster et al., 2005), which enhances the likelihood of catastrophic flooding of the delta plain (Szabo et al., 2016) and increases coastline erosion (Slott et al., 2006). In some areas, this process is exacerbated by increased subsidence rates driven by groundwater and hydrocarbon extraction (Syvitski et al., 2009). Sustainable delta development is a serious environmental challenge (Bahgat, 2018; Blum \& Roberts, 2009; Day et al., 1997; Ibàñez et al., 1997; Kim et al., 2009; Paola et al., 2011). Evidently, understanding the dynamics of deltaic systems is of great economic and societal importance. As such, it is pertinent to constrain the rates at which modern deltaic systems prograde (Aadland \& Helland-Hansen, 2016; Caldwell et al., 2017; Edmonds et al., 2017), as this parameter is important in describing their evolution. In this paper, we present empirical data constraining progradation rates measured directly adjacent to the fluvial entry points of modern deltaic coastlines, and we discuss how these observations relate to the overall evolution of both modern and ancient deltaic coastlines.

Modern deltaic progradation rates are usually quantified and discussed on a case-by-case basis in studies of individual deltas (e.g., Hori et al., 2001; Ta et al., 2002), and these observations have not been combined in metastudies offering general constraints on modern progradation rates. One exception is the progradation rate data set of Sadler and Jerolmack (2014), but this data set contains progradation rates derived from many 
different depositional settings and time spans ranging from seconds to as long as hundreds of millions of years. Thus, the data set is not compiled to provide constraints on the progradation rates of modern deltaic coastlines specifically. There are numerical inversion methods to estimate the progradation rates characterizing shallow marine deposits by using shoreline trajectories recorded in ancient deposits (Patruno et al., 2015) or by using forward stratigraphic models (Charvin et al., 2011). However, it is challenging to find representative empirical rates with which to compare the estimated progradation rates. When delta progradation rates have been needed to answer questions about shelf transit times (Burgess \& Hovius, 1998), researchers have had to approach delta progradation as a mass balance problem and used the much better constrained fluvial suspended sediment transport rates (see Syvitski \& Milliman, 2007; Syvitski et al., 2003) instead of direct progradation rates. Numerical and analog modeling of deltaic systems provides insight into how the morphology and development of this landform depends on allogenic and autogenic parameters (Ashton \& Giosan, 2011; Edmonds \& Slingerland, 2007; Geleynse et al., 2010; Kim et al., 2006; Mahon et al., 2015; Paola et al., 2009; Reitz et al., 2010; Straub et al., 2013, 2015; Swenson et al., 2005); nevertheless, the experiments must be interpreted based on empirical data. Progradation rates derived from modern deltas represent one obvious empirical constraint that would aid interpretation and validation of experimental results.

We address this need by quantifying localized progradation rates that represent shoreline changes occurring directly adjacent to the fluvial entry points of modern deltaic systems and looking for predictive relationships between these rates and catchment and climate parameters. This sampling methodology is motivated by a simple model of subaerial delta evolution: the change in the subaerial delta area equals the input of new sediment, primarily delivered by the fluvial system, minus the amount of sediment removed by basinal processes. Note that this model ignores the effect of relative sea level changes, which can be an important driver of shoreline changes in modern (Berglund, 2004) and ancient systems (Van Wagoner et al., 1988). We know that fluvial processes bring sediment to the shallow marine environment (Milliman \& Syvitski, 1992; Syvitski \& Milliman, 2007; Syvitski et al., 2003, 2005) and that basinal processes, such longshore drift and cross-shore sediment transport, remobilize the deposited sediment (Ashton \& Murray, 2006; Komar, 1971). The marine processes act over the entire shoreline, and their efficiency is generally very difficult to constrain (Mason \& Coates, 2001). We deal with this problem by focusing on depositional features in the area where the fluvial system interacts the most with the shallow marine environment, that is, at the river outlets. In this way, we aim to obtain progradation rate measurements that predominantly reflect the fluvial component of the subaerial delta evolution, with as small as possible an overprint of marine processes. We are not arguing that a river-centric approach is enough to describe the evolution of modern deltaic coastlines; rather, our idea is that these localized progradation rates are particularly correlated with the amount of new sediment brought to the coastline by the fluvial system and that this parameter is important in the mass balance budget of the entire deltaic coastline.

To achieve this goal, we use Landsat-derived satellite images to identify plan view changes in the subaerial morphology of 331 modern deltas, from which we can quantify localized progradation rates that occur adjacent to the fluvial entry points at the deltaic shorelines. These rates are compared with parameters in the Milliman and Farnsworth (2013) data set, a well-documented compilation of climate, catchment, and fluvial discharge parameters, many of which are feasible to constrain in ancient systems (Eide et al., 2017; Helland-Hansen et al., 2016; Sømme et al., 2009), as well as additional parameters quantifying properties of the depositional sink such as water depth extracted from General Bathymetric Chart of the Oceans (GEBCO) bathymetric data (Jakobsson et al., 2012) and wave energy extracted from Archiving, Validation and Interpretation of Satellite Oceanographic data (AVISO+)-derived data products (AVISO+, 2009). We take advantage of the Google Earth Engine (Gorelick et al., 2017) to create our rate compilation. This tool is a cloud platform that facilitates analysis of geospatial data with an extensive catalog of readily available remote sensing data. Previously, Google Earth Engine has been used to map changes in global surface water (Donchyts et al., 2016; Pekel et al., 2016) and to map the global distribution of shoreline changes affecting sandy beaches (Luijendijk et al., 2018).

Our objective is to present our progradation rate measurements and to quantify the relationship between these rates and catchment parameters by presenting empirical models of the data. We also briefly discuss a possible application of the main result within sedimentological and stratigraphic analysis. 


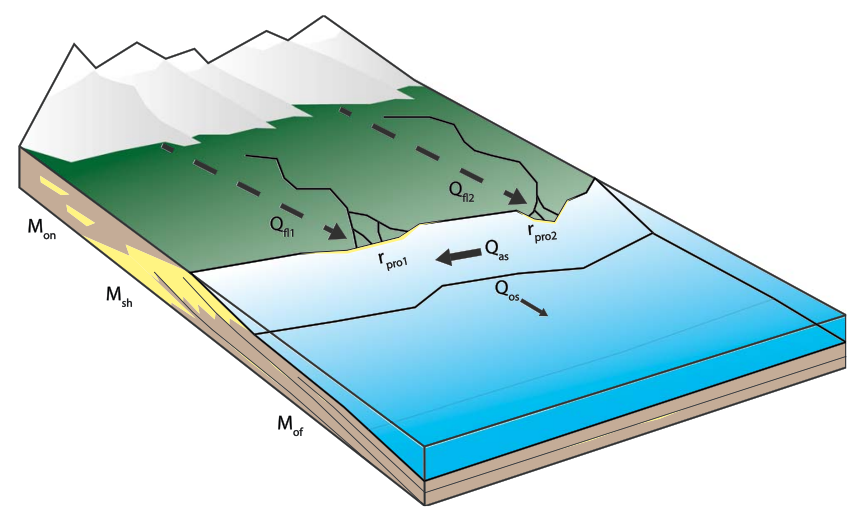

Figure 1. This figure shows a simplified model of subaerial delta expansion rates $r_{\text {pro }}$. The model has three reservoirs-onshore, shallow marine, and offshore-and three sediment fluxes - the fluvial sediment flux, the alongshore sediment flux, and the offshore sediment flux. This model conceptualizes an upland sediment source delivering sediment to a depositional system characterized by shoreline clinoforms and subaqueous clinoforms.

\section{Method}

\subsection{Conceptual Model of the Depositional Systems Sampled for Progradation Rates}

This paper analyzes changes in the shoreline positions of modern deltaic coastlines that have occurred over the last 30 years. Several studies link comparable geomorphological changes to sediment load transport rates (e.g., Constantine et al., 2014; Ham \& Church, 2000; Martin \& Church, 1995; Pelpola \& Hickin, 2004). Ultimately, a change in shoreline position must be associated with a change in the amount of sediment deposited at the shoreline or by a change in relative sea level (Berglund, 2004; Van Wagoner et al., 1988). We can formalize the former mechanism by considering some relevant sediment reservoirs and the fluxes between them in a typical siliciclastic depositional system (Figure 1). In the context of our analysis, we recognize three principal sediment reservoirs: onshore deposits $M_{o n}$, shallow marine deposits $M_{s h}$, and offshore deposits $M_{o f}$. Assuming then that the progradation rate of the shoreline is proportional to the amount of sediment delivered to the shallow marine environments, this rate is described by the following relationship:

$$
\sum_{i=1}^{n} r_{\mathrm{pro}}(i)=c \frac{\mathrm{d} M_{\mathrm{sh}}}{\mathrm{d} t},
$$

where $c$ is some proportionality coefficient that is reasonably expected to be dependent on the height and the width of the shoreline clinoform investigated and $\mathrm{n}$ is the number of river outlets interacting with $M_{\mathrm{sh}}$.

In this model, the reservoirs are connected by three main sediment fluxes. The ultimate source of sediment is represented by fluvial systems that transport sediment downslope. This flux $Q_{\mathrm{fl}}$ interacts with all three reservoirs. Marine processes drive alongshore sediment transport that introduces new sediment and erodes and removes previously deposited sediments. Only the part of the alongshore sediment flux $Q_{\mathrm{as}}$ that interacts with the shallow marine deposits is relevant for progradation rates. The offshore sediment flux $Q_{\mathrm{os}}$ is sourced in the shallow marine deposits and terminated in the offshore environments. Mathematically, the system can be summarized as follows:

$$
\begin{gathered}
\frac{\mathrm{d} M_{\mathrm{on}}}{\mathrm{d} t}=c_{\mathrm{on}} \sum_{i=1}^{n} Q_{f l}(i) \\
\frac{\mathrm{d} M_{\mathrm{sh}}}{\mathrm{d} t}=Q_{\mathrm{as}}-Q_{\mathrm{os}}+c_{\mathrm{sh}} \sum_{i=1}^{n} Q_{f l}(i) \\
\frac{\mathrm{d} M_{\mathrm{of}}}{\mathrm{d} t}=Q_{\mathrm{os}}+c_{\mathrm{of}} \sum_{i=1}^{n} Q_{\mathrm{fl}}(i) \\
c_{\mathrm{on}}+c_{\mathrm{sh}}+c_{\mathrm{of}}=1
\end{gathered}
$$

where $n$ is the number of fluvial systems terminating at the shoreline and $c_{\mathrm{on}}, c_{\mathrm{sh}}$, and $c_{\mathrm{of}}$ are coefficients that quantify the ratios of the sediment transported by the fluvial system that are extracted by the onshore, shallow marine, and offshore deposits, respectively. 


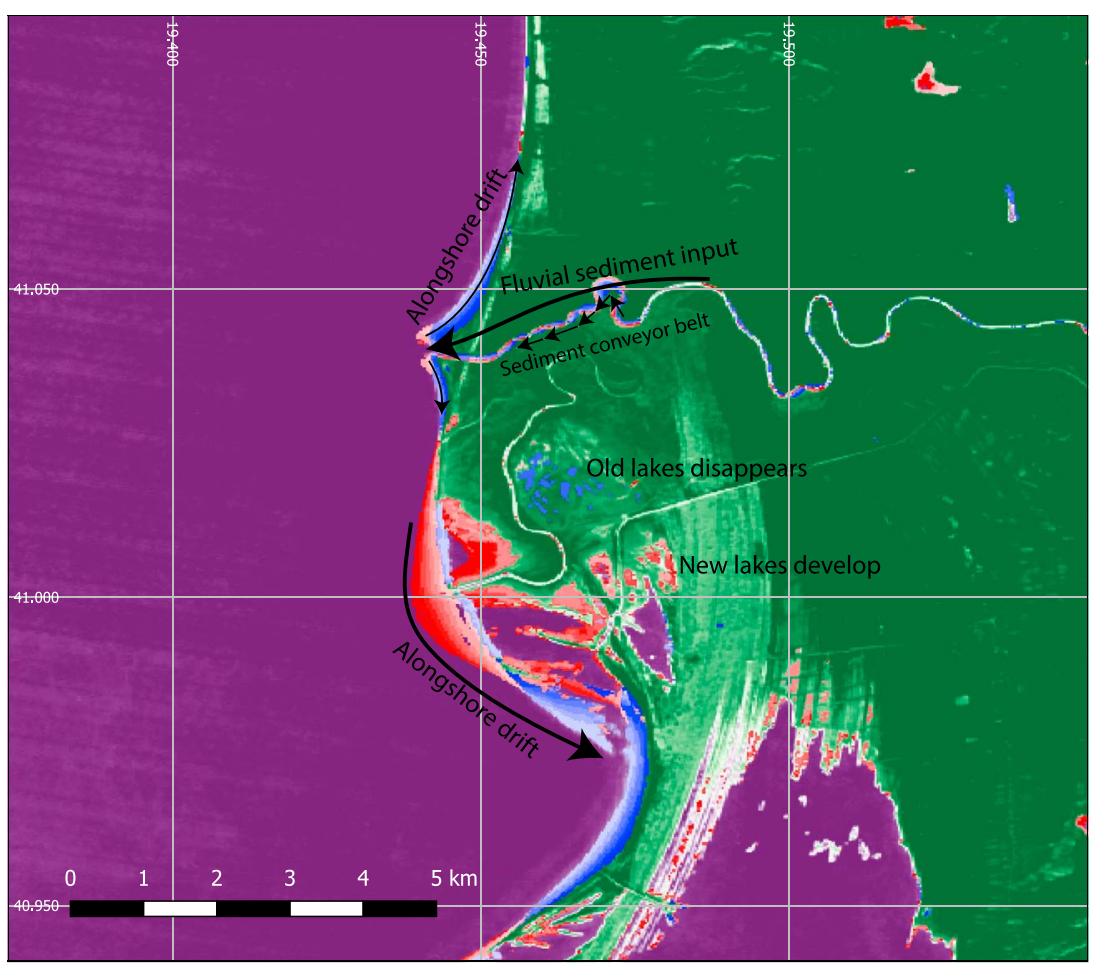

Figure 2. This image shows water and land changes occurring at the Shkumbini Delta of Albania, a typical wave-dominated deltaic coastline. The blue areas represent areas of sediment deposition; red, areas of sediment erosion; green, land; and purple, water. There is a fluvial system delivering sediment to the coastline through a sediment conveyor belt of fluvial point bars. The fluvial system terminates in a progradational protrusion at the coastline. Diffusive processes associated with waves redistribute the deposited sediment giving the protrusion a concave shape, while a protruding abandoned lobe to the south of the active lobe is being eroded by marine action. Its sediment is redeposited in the bay to the south gradually producing a more linear coastline. Note that the area of progradation in the bay is only $10 \%$ larger than the eroded area of the abandoned lobe.

Nonprogradational shorelines can arise in this system if $c_{\mathrm{sh}}$ is decreased, that is, if less of the sediment transported by the fluvial system is deposited in the shallow marine environment. Similarly, basinal processes can become dominant if $Q_{o s}$ increases or if $Q_{\text {as }}$ becomes negative, that is, by an increase in offshore-directed sediment transport or by removal of more sediment by longshore drift than is supplied. Many of these concepts can be recognized in the time-lapse of the Shkumbini Delta of Albania presented in Figure 2. The figure shows how basinal processes dominate the evolution of the coastline away from fluvial entry points, while the fluvial signal is dominant in the region where the fluvial system connects with the shoreline.

\subsection{Data Sets}

\subsubsection{Satellite Images}

We use Google Earth Engine (Gorelick et al., 2017) to quantify plan view changes in the land cover of modern prograding deltaic shorelines by analyzing Landsat 4, 5, 7, and 8 thematic mapper-derived, top-of-atmosphere corrected reflectance images with a resolution of $30 \mathrm{~m}$ acquired in the period 1984-2015 (U.S. Geological Survey, 2016). These images have a temporal granularity of approximately 16 days (Gorelick et al., 2017), although the spatial and temporal coverage of thematic mapper-derived images is uneven, with significant increases in acquisition rate in 1999 and 2013 (Pekel et al., 2016). On average, every location is covered by 500 images, although this number may be as high as 2,000 depending on location (Gorelick et al., 2017).

\subsubsection{Parameters in Our Data Set}

The objectives of this study are to quantify localized progradation rates that occur directly adjacent to the fluvial entry points of modern deltaic systems and to look for predictive relationships between these rates 


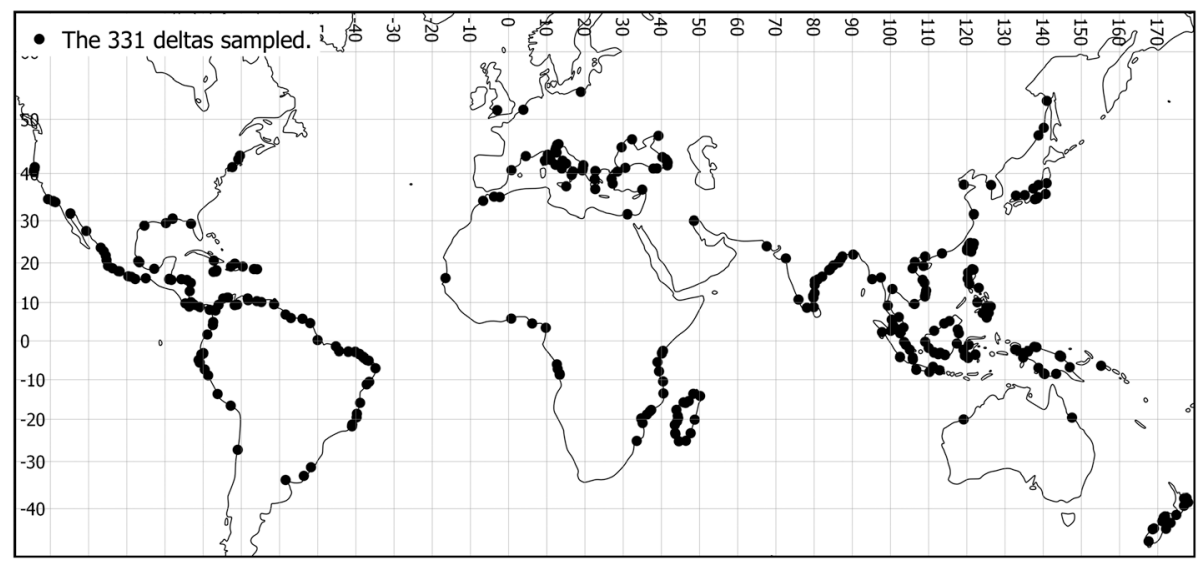

Figure 3. The black points represent the 331 deltas investigated in this study. Coastline polygon is from OpenStreetMap Contributors (2017).

and catchment and climate parameters. To accomplish these tasks, we created a data set comprising three different types of parameters:

1. Our measured progradation rates: the target parameter to predict using an empirical model.

2. Climate and catchment properties: the parameters to use in predicting the progradation rates.

3. Parameters quantifying some key basinal processes: values used to quality check how strong the basinal signal is in our rate estimates.

Localized progradation rates. We investigate coastline changes at 331 deltas (Figure 3 ) selected from the Milliman and Farnsworth (2013) database. For all the deltas combined, we quantify 2,780 rates of shoreline progradation and retreat. These rates represent durations from as short as 2 years to as long as 31 years. To avoid biasing our analysis toward the deltas with several progradation rate estimates, we reduce the number of data points by calculating average progradation rates for each delta where we detect net progradation. This process reduces the number of rates in our data set to 137 progradation rates.

Climate and catchment properties. Our data set includes climate and catchment parameters derived from three different sources: we obtain a range of relevant climate and catchment parameters from the Milliman and Farnsworth (2013) database, we extract maximum catchment elevation measurements from a digital elevation model provided by U.S. Geological Survey (U.S. Geological Survey-Global 30 Arc-Second Elevation, 2016), and we extract mean catchment temperatures from the Climate Prediction Center Global Temperature data provided by National Oceanic and Atmospheric Administration/Oceanic and Atmospheric Research/Earth System Research Laboratory (Climate Prediction Center, 2018).

In our analysis, we extract the following catchment and discharge parameters from the Milliman and Farnsworth (2013) database: water discharge, total suspended sediment load, predam suspended sediment load, predam water discharge, catchment area, and catchment length. The unused parameters of the data set are combinations of these parameters, categorical data not suitable for use in our regression model or not constrainable in ancient systems. The data coverage of each of these fields is not complete, meaning that some parameters are lacking for some of the data points. Note that the fluvial discharge data are derived from the seawardmost hydrological station of each fluvial system, while the total suspended sediment load data are derived from case studies quantifying the sediment loads of the rivers (Milliman \& Farnsworth, 2013). This situation means that the suspended sediment load data may be derived from more upstream locations than the water discharge measurements and that the suspended sediment load data might be biased by preferential sampling during high-discharge events (Milliman \& Farnsworth, 2013).

Basinal processes. In our analysis, we assume that by extracting delta progradation rates from the part of the coastline that is closest to fluvial entry points, we are sampling progradation rates that are more reflective of fluvial processes than basinal processes. We include a few parameters that capture key basinal processes in our data set in order to test this assumption. If we find that these basinal parameters are very predictive of the progradation rate, such a result is a strong indication that our assumptions are incorrect. The basinal parameters we include in our data set are nearshore water depth extracted from General Bathymetric Chart 
of the Oceans (GEBCO) bathymetric data (Jakobsson et al., 2012), magnitude of the tectonic strain rates local to the deltaic coastline extracted from a second invariant of strain rate map that is part of the global strain rate model of Kreemer et al. (2000), isostatic uplift and subsidence rates at the deltaic coastline extracted from GRACE Tellus-derived glacial isostatic adjustment maps (GRACE Tellus, 2004; Peltier, 2004; Wahr \& Zhong, 2012), and mean significant wave height extracted from AVISO+ data products (AVISO+, 2009). The three former parameters are possible proxies for relative sea level changes, while the mean significant wave height is a possible proxy for the wave-driven alongshore sediment transport rate (Ashton \& Murray, 2006; Komar, 1971).

\subsection{Estimating the Progradation Rates}

2.3.1. Classification of Landsat Images

Quantification of global changes in surface water can be approached by analyzing many images and averaging some index with high water-land contrast (Donchyts et al., 2016; Pekel et al., 2016). We are interested in quantifying changes in the land cover adjacent to water bodies and approach this problem in a comparable manner. We classify image regions as water or land by using the modified normalized difference water index (MNDWI; equation (6)) of Xu (2006):

$$
\text { MNDWI }=\frac{\rho_{\text {green }}-\rho_{\text {SWIR }}}{\rho_{\text {green }}+\rho_{\text {SWIR }}}
$$

where $\rho_{\text {green }}$ is the green band and $\rho_{\text {SWIR }}$ is the shortwave infrared band of the satellite images. We calibrate the MNDWI values to be consistent across the different Landsat satellites, and we use FMASK (Zhu \& Woodcock, 2012) to mask cloud, cloud-shadow, and snow-covered areas. To reduce the impacts of noise and of short-term variations in water cover caused by tides and episodic flooding, we calculate an average MNDWI value for multiple Landsat scenes. By estimating MNDWI averages of many images, we emphasize the long-term changes in the shoreline morphology. Quality control of our classification scheme is accomplished by comparing our results with a high-resolution coastal digital elevation model (National Oceanic and Atmospheric Administration, 2016) representing Myrtle Beach, South Carolina, USA. This comparison demonstrates that the MNDWI averages capture nearshore coastline morphologies well.

Note that the uneven spatial and temporal coverage of thematic mapper-derived Landsat scenes (Pekel et al., 2016) limits the possibility of a uniform sampling of coastline changes over the entire 1984-2015 period. To ensure that each land-water classification is of sufficient quality to produce a representative rate estimate, we generate land-water classification only for periods where at least 20 unique satellite images were acquired. This approach means that we have more progradation rate estimates for some deltaic systems than others.

To detect changes in land and water cover, we compare the difference in the index associated with classification generated for different periods. Further details of our image analysis and classification scheme are described in the supplementary material.

\subsubsection{Sampling of Deltas}

We quantify the coastline changes occurring at 331 of the river systems described in the Milliman and Farnsworth (2013) database to create our rate compilation. For each rate estimate, we require two land-water classifications of the same delta that represent different periods. By comparing the state of the coastline at the two different periods, we generate geospatial vector data representing areas of coastline progradation and areas of shoreline retreat. We consider any water-to-land transition as progradation and any land-to-water transition as shoreline retreat.

The vector data capture all the changes occurring along the coastline. However, we are interested only in quantifying the shoreline changes driven by local fluvial systems. Thus, the shoreline changes driven by relative sea level change and marine processes are sources of noise that interferes with the signal we are interested in capturing. We address this problem by manually inspecting the changes detected at each delta and removing the coastline changes that are not directly adjacent to a fluvial entry point and those that are obviously related to human activity.

We define our progradation rates $r_{\text {pro }}$ as follows:

$$
r_{\text {pro }}=\frac{A_{\text {dep }}-A_{\text {ret }}}{t}
$$


Table 1

This Table Summarizes the Distribution of Labels Among the Deltas Sampled in This Study

\begin{tabular}{lccc}
\hline Label & Prograding & Total & $p$ \\
\hline Fluvial dominated & 12 & 15 & 0.8 \\
Tidal dominated & 27 & 60 & 0.5 \\
Wave dominated & 79 & 163 & 0.5 \\
Linear shape & 54 & 110 & 0.5 \\
Protruding shape & 71 & 136 & 0.5 \\
Funnel shape & 9 & 18 & 0.5 \\
\hline
\end{tabular}

Note. The first three rows represent labels derived from the Galloway classification of deltas, while the three last rows are geometric descriptions of the shape of the deltas. The second column represents the distribution of the labels among the prograding deltas, while the third column is the distribution of the labels among all 331 deltas sampled. The fourth column quantifies the probability of a delta with the given label prograding.

where $A_{\text {dep }}$ is the area where a water-to-land transition has occurred, $A_{\text {ret }}$ is the area where a land-to-water transition has occurred, and $t$ is the duration over which the detected changes occurred. We classify a delta as prograding if the progradation rate $r_{\text {pro }}$ is positive.

A KMZ file with all the coastline changes identified by analysis of the Landsat data and a KMZ file with the subset of these changes located in proximity to fluvial entry points are available in the supporting information. The supporting information data also contain a more detailed description of our sampling methodology.

\subsection{Model Selection}

Based on the lognormal distribution of parameters in the data set and the power law form of established sediment flux models (see Syvitski et al., 2003; Syvitski \& Milliman, 2007), we assume that the data are best described by a power law equation; consequently, we transform the data set by computing the logarithm of each feature before fitting linear models to the data. We evaluate the performances of multiple regression models that predict the transformed progradation rates as linear functions of different combinations of the following transformed parameters: water discharge, predam water discharge, predam suspended sediment load, total suspended sediment load, catchment area, catchment length, mean catchment temperature, maximum catchment elevation, nearshore water depth, strain rate at the coastline, isostatic uplift at the deltaic coastline, and significant wave height.

Our training data is a high-dimensional data set with unevenly distributed feature value coverage, and in order to select the best model, we use the following cost function $c_{k}$ :

$$
c_{k}=R^{2} \sqrt{n_{s}},
$$

where $k$ is the number of parameters used in the regression, $n_{s}$ is the number of samples used in the regression, and $R^{2}$ is the coefficient of determination of the model for the observed progradation rates. That is, $c_{k}$ quantifies the goodness of fit of a model with $k$ input parameters normalized by the amount of training data available. The $n_{s}$ term is necessary because of the uneven coverage of parameter values in the Milliman and Farnsworth (2013) database.

\subsection{Evaluating the Impact of Marine Processes on the Model}

This study produces a formula predicting progradation rates at the fluvial entry points of deltaic shorelines. A key assumption of the analysis is that progradation rates measured at the fluvial entry points of the deltaic shoreline are more dependent on fluvial processes than on basinal processes, at least relative to other parts of the deltaic coastline. However, basinal processes are a first-order control on delta development, and it is necessary to assess their impact on the model produced. To do this assessment, we label most of the 331 deltas sampled according to basic categories of the Galloway classification scheme (Galloway, 1975) and according to basic geometric descriptions of their shape. Key statistics of this labeling are summarized in Table 1. Both the Galloway classification and the shape of the delta are very dependent on the basinal processes acting on the delta; consequently, our labeling allows us to extract subsets from our data set that are expected to be 


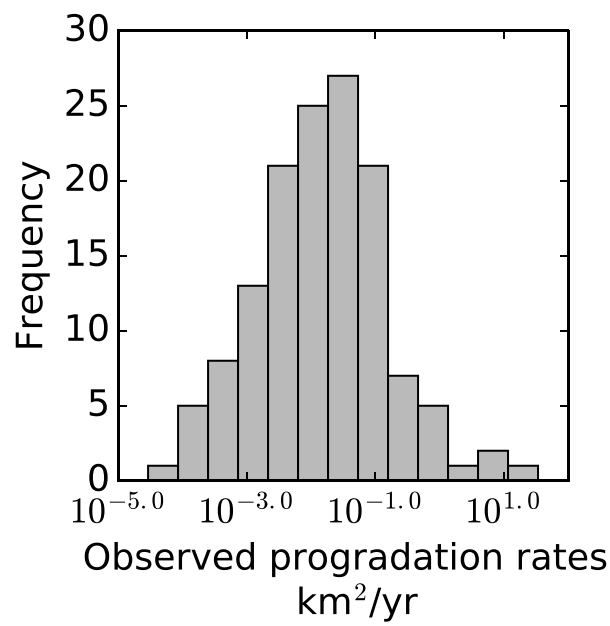

Figure 4. This figure shows the distribution of the progradation rates we measured at the fluvial entry points. Observe that the rates span 6 orders of magnitude and have a lognormal distribution. similarly affected by basinal processes. Our hypothesis is then that our sampling methodology has limited the signal of basinal processes in our rate estimates. One way of falsifying this hypothesis is to see if there is a consistent error in the prediction of the model when it is used on subsets of the data that have a consistent bias in terms of basinal processes.

\section{Results}

We have two main findings: a compilation of progradation rates measured at modern river outlets and models relating these rates to catchment and climate properties.

\subsection{Distribution of Rates}

We classify only 137 of the 331 systems probed in this study as prograding. From these systems, we record progradation rates $\left(\mathrm{km}^{2} /\right.$ year $)$ that span 6 orders of magnitude with a lognormal distribution $(\sim \operatorname{lognormal}(\mu=$ $\left.-1.85, \sigma^{2}=1.01\right)$ ). The $P$ value for normality (d'Agostino, 1971; Jones et al., 2014) of the rate population is 0.99 (Figure 4). The distribution of the sample population is biased by the 30 -meter spatial resolution of the Landsat scenes, which represents the lower sampling limit.

\subsection{Best Model of Progradation Rates}

By optimizing for the maximum of the cost function (equation (8)), we find that the following formulas provide the best model of the progradation rates given the parameters available in the data set:

$$
\begin{array}{rllll} 
& k & R^{2} & n_{s} & \sigma \\
r_{\text {pro }}=10^{-2.5} Q_{w}^{0.78} & 1 & 0.46 & 113 & 0.7 \\
r_{\text {pro }}=10^{-2.5} Q_{w}^{0.59} Q_{s}^{0.34} & 2 & 0.65 & 71 & 0.7 \\
r_{\text {pro }}=10^{-4.0} Q_{w}^{0.55} Q_{s}^{0.35} T^{1.1} & 3 & 0.67 & 71 & 0.6 \\
r_{\text {pro }}=10^{-4.0} Q_{w}^{0.40} Q_{s}^{0.33} T^{1.1} A^{0.17} & 4 & 0.68 & 71 & 0.6 \\
r_{\text {pro }}=10^{-3.7} Q_{w}^{0.42} Q_{s}^{0.34} T^{1.1} A^{0.17} D^{-0.14} & 5 & 0.68 & 71 & 0.6 \\
r_{\text {pro }}=10^{-3.8} Q_{w}^{0.42} Q_{s}^{0.32} T^{1.1} A^{0.16} D^{-0.15} R^{0.1} & 6 & 0.68 & 71 & 0.6
\end{array}
$$

where $r_{\text {pro }}\left(\mathrm{km}^{2} /\right.$ year $)$ is the median progradation rate, $Q_{w}\left(\mathrm{~km}^{3} /\right.$ year $)$ is the water discharge of the associated fluvial system, $Q_{S}$ (MT/year) is the total suspended sediment delivered by the fluvial system, $A\left(1 \mathrm{e} 3 \mathrm{~km}^{2}\right)$ is the catchment area, $R(\mathrm{~km})$ is the maximum elevation of the catchment, $T\left({ }^{\circ} \mathrm{C}\right)$ is the average catchment temperature, $D(\mathrm{~m})$ is the nearshore water depth, $k$ is the number of parameters used in the regression, $\sigma$ is the standard deviation of the detrended lognormal rate distribution (see Figure 5), and $n$ is the number of data points used in the regression. Note that $\log \left(r_{\text {pro }}\right)$ represents the mean of a lognormal rate population (Figure 5), which is equivalent to the median of the rate population.

The formulas have an error of approximately plus-or-minus 1 order of magnitude, with the detrended log-rate populations having standard deviations between 0.7 and 0.6 magnitude (Figure 5). There is a significant improvement in the fit of the models (see Figure 6) when they are based on at least two parameters (equation 10-14) rather than only one parameter (equation (9)). Weighing the complexity associated with an additional parameter against the improvement in the goodness of fit, we argue that equation (10) is the best model for our data set.

We note that there is a significant improvement in the goodness of fit of the models when they are trained on multiple parameters (equations 10-14) rather than just one parameter (equation (9)). This result indicates that either the particular subset of 71 data points used to train the multiparameter models is more correlated 

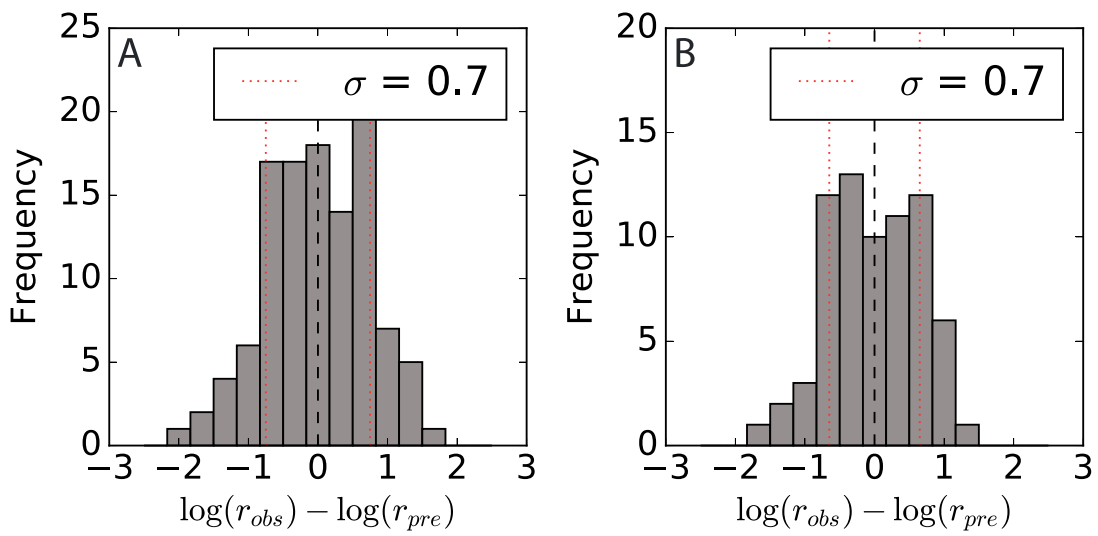

Figure 5. This figure shows the distribution of the empirical data that have been detrended by using the formulas found in this study. The formulas used in (a) and (b) correspond with those used in Figures 6a and 6b, respectively. Note that the detrended populations appear to have a lognormal distribution. The black stippled line defines the mean of the lognormal distribution. The red stippled lines define the standard deviation of the lognormal distributions. $P$ values for normality (d'Agostino, 1971; Jones et al., 2014) are 61.9 and 40.2 for (a) and (b), respectively.

with the progradation rates or the variation in the progradation rate is best captured by multiple parameters. To evaluate these two options, we do a second regression training of the one-parameter model on only the 71 data points used to train the multiparameter models. This process yields the following result:

$$
r_{\text {pro }}=10^{-2.6} Q_{w}^{0.86} \quad R^{2}=0.62 \quad n=71 \quad \sigma=0.7
$$

This result favors the former mechanism; that is, it indicates that the subset of the data used to train the multiparameter models is better correlated with our progradation rate measurements than the data set is in general.

\subsection{Impact of Marine Processes on Model}

We compare the prediction of equation (10) with subsets of the empirical data defined by the labels outlined in Table 1. In this way, we evaluate whether the model represented by equation (10) is biased by basinal processes. The statistics summarizing this comparison are presented in Table 2.

This table shows that the mean errors of all subsets, except for the subset representing deltas with funnel-like shapes, are well within a standard deviation of the predictions of equation (10). The standard deviations are also consistent with equation (10). However, the progradation rates of deltas with funnel-like shapes and, to a lesser extent, those that are classified as tide dominated are underpredicted by equation (10). These deltas
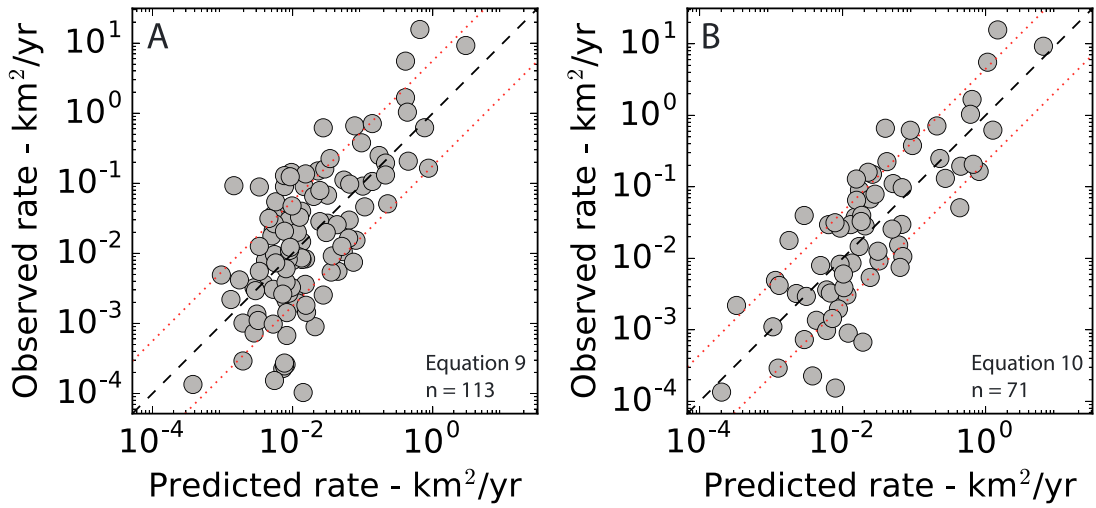

Figure 6. Panels (a) and (b) show progradation rates measured directly adjacent to fluvial entry points plotted against progradation rates predicted using our one- and two-parameter models, respectively. The equation used and the number of data points $n$ plotted are indicated in the lower right corner of each subfigure. The black stippled line defines a one-to-one relationship between the observed and predicted rates. The red stippled lines define the standard deviation of the lognormal distribution produced by detrending the empirical data (see Figure 5). 
Table 2

This Table Summarizes the Distribution of the Normalized Rate Data for Each of the Labeled Subsets of the Data Set Analyzed in This Study

\begin{tabular}{lcccc}
\hline Label & $\mu$ & $\sigma$ & $n$ & $P$ value \\
\hline Fluvial & 0.02 & 0.7 & 9 & 30 \\
Tidal & 0.3 & 0.8 & 16 & 5.1 \\
Wave & -0.1 & 0.7 & 40 & 34.7 \\
Linear & -0.2 & 0.8 & 23 & 31 \\
Protruding & 0.03 & 0.6 & 44 & 38 \\
Funnel & 0.6 & 1 & 9 & 82 \\
\hline
\end{tabular}

Note. The second column gives the mean of the normalized rate data, that is, $\log \left(r_{\text {obs }}\right)-\log \left(r_{\text {pre }}\right)$, while the third gives its standard deviation. The fourth indicates the number of deltas that the presented statistics are based on. The last column gives the $P$ value for normality of the normalized rate distribution (d'Agostino, 1971; Jones et al., 2014).

represent approximately $7 \%$ and $25 \%$ of the deltas sampled, respectively (Table 1 ). Note that the deltas labeled as having funnel-like shapes are a subset of those classified as tide dominated. Redoing the analysis with a composite class of "tide dominated" and not having a funnel-like map view shape produces the following statistics: $\mu=0.09, \sigma=0.6, \mathrm{n}=14$, which are consistent with those of equation (10). This result indicates that the river-centric approach employed in this study is not justified when investigating funnel-shaped deltas.

The preceding section presents a very qualitative interpretation of the distribution of the normalized rate data; unfortunately, a more rigorous comparison of the normalized rate distributions is not feasible considering the small sample set and their very low $p$ values for normality.

\section{Discussion}

\subsection{Can Basinal Processes be Ignored When Investigating Progradation Rates Measured Close} to River Outlets?

The basic assumption of our analysis is that by extracting delta progradation rates from the part of the coastline that is closest to fluvial entry points, we are sampling progradation rates that are more reflective of fluvial processes than basinal processes, and we use this assumption to justify considering a river-centric model of these progradation rates. We have evaluated this assumption by using two approaches. One approach is to include parameters quantifying basinal properties in the model-finding phase of our analysis and to evaluate how correlated these parameters are with the progradation rates. In the other approach, we define subsets of the data sets that are clearly and consistently biased in terms of the basinal processes acting on the delta, and we evaluate whether this bias is reflected in the empirical models.

In the context of the basinal parameters in the data set, we find that only nearshore water depth improves our statistical model; however, it is clear from equation (13) that this improvement is insignificant. Consequently, we conclude that neither of the basinal parameters we added to the data set is sufficiently correlated with our progradation rate estimates to justify rejecting our basic assumption. In the context of our labeled subsets, we find that most of them do not display obvious bias when compared with our best model of the data (equation (10)); the exception is the deltas that were found to have a funnel-like shape in map view. Our model significantly underestimates the progradation rates of these deltas, and we interpret this as evidence that our basic assumption is not applicable when investigating deltaic coastlines with a funnel-like shape.

Still, our basic assumption seems to hold up reasonably well to both these tests. We are not proposing that basinal processes have an insignificant effect on modern deltaic coastlines. Even in the simplest model of subaerial delta development, both fluvial sediment input and basinal processes are first-order controls on the subaerial delta progradation rate. However, we do argue that the simplification presented herein provides a first-order constraint of the pace of deltaic deposition. Considering Figure 2, wave-driven longshore drift affects the entire coastline, while the effect of the fluvial system bringing sediment to the shoreline is localized to a progradational protrusion at the river outlet. By estimating the rate at which this progra- 
dational protrusion grows, we obtain a meaningful constraint on the fluvial contribution to the shoreline progradation.

\subsection{Water Depth, Relative Sea Level Change, and Measured Progradation Rates}

As conceptualized in equation (1), it seems reasonable that water depth should be an important parameter when predicting delta progradation rates. However, this effect is not what we find when we search for the best model of our data. Our analysis indicates that including a term for the near-shore water depth has an insignificant effect on the goodness of fit of the model. Similarly, considering that deltaic shorelines are very low gradient environments where small perturbations in topography can result in significant changes in shoreline position, it seems reasonable to expect that parameters quantifying relative sea level changes should be important parameters for predicting delta progradation rates. However, we find that parameters quantifying the strain rate and isostatic uplift/subsidence at the deltaic coastline, that is, parameters related to the local relative sea level change, are not predictive of our measured progradation rate. These observations contradict expectations.

One possible reason for this inconsistency relates to a bias in our data set. Isostatic uplift is most pronounced in areas that have recently been covered by large ice sheets. It is clear from Figure 3 that these areas are underrepresented in our data set. Furthermore, it is worth emphasizing that accommodation space and relative sea level changes are concepts that were developed to analyze ancient deltaic deposits. This type of analysis deals with processes that act over geological timescales, and it is not clear that these concepts apply to the relatively instantaneous depositional processes occurring on modern deltaic shorelines. Sediment accumulation over geological timescales in a continental setting is predominantly controlled by subsidence, while the instantaneous depositional processes acting in modern environments are largely disconnected from the long-term subsidence of the local terrain (Ager, 1993). That is, there is a fundamental difference in the control of where depositional processes accumulate sediment and where geological processes preserve this sediment over geological time. Lastly, it is demonstrated empirically that the thickness of shoreface clinoforms have a very limited size distribution (Patruno \& Helland-Hansen, 2018) and that modern shoreface profiles are generally considered to be determined by the local wave climate and sediment grain-size composition (Dietz, 1963; Pilkey et al., 1993). If so, then perhaps the depth of the prograding shoreline clinoform is not such an important parameter to consider because it is constrained to a relatively limited and uniform range of possible values.

\subsection{Does Equation (10) Generalize to Other Data Sets?}

In section 3.2, we highlight a power law relationship among deltaic progradation rates, water discharge, and sediment supply. We note that power law relationships with exponents in the range of 1-2.5 between sediment load transport rates and fluvial water discharge are reported in several studies (Emmett, 1981; Islam et al., 1999; Lane, 1954; Mulder \& Syvitski, 1995; Nanson, 1974). There are also reports of a power law relationship with an exponent of approximately 1.5 between bed load and suspended sediment load transport rates (Métivier et al., 2004; Meunier et al., 2006), although a meta-analysis combining data from multiple studies indicates that this positive correlation is not accurately described by a power law (Métivier et al., 2004; Meunier et al., 2006; Nanson, 1974; Turowski et al., 2010; Williams \& Rosgen, 1989).

Most studies discuss the correlation between water discharge, suspended sediment load, and bed load transport rates one against another, and there are no obvious studies linking bed load transport rates to water discharge and suspended sediment load in a combined way as indicated by our study (equation (10)). However, there are public data sets where these specific relationships can be investigated using independent data. The Williams and Rosgen (1989) data set contains 1930 data points with water discharge, suspended sediment load, and bed load parameters recorded from 93 U.S. streams. The three parameters are highly correlated, and the data points indicate a line on three-dimensional log-log-log plots of water discharge versus suspended sediment load versus bed load. Consequently, a model derived by a multiple regression based on two parameters is only marginally better than one generated by simple regression of either of the two other parameters individually. However, when we do multiple regression on the logarithm of all three parameters of the data set together (equation (16)), we do find a model that looks like the one highlighted in this study (equation (10)); that is, we find

$$
g_{s}=10^{1.75} Q^{0.73} Q_{s}^{0.44} \quad R^{2}=0.80 \quad n=1887
$$


In particular, the similarities between the two formulas (equations (10) and (16)) are that they both have the same input parameters and that these relations are associated with comparable exponents.

\subsection{Applicability of Models to Ancient Systems}

Our motivation for compiling the progradation rate data set is to produce some empirical data on the rate of modern delta development. We are particularly interested in using these observations as constraints on the progradation rates associated with delta front deposits in sedimentary rocks. However, it is not obvious that the data set we generated is representative of ancient source-to-sink systems. The rate distribution indicated by the data set (Figure 4) may be biased if the modern deltaic systems sampled are not a representative selection of deltas as they have occurred throughout geological history, and the models (equations (9)-(13)) we found may only make meaningful predictions of modern systems. In summary, we have two major concerns when applying the models to the analysis of ancient sedimentary rocks:

i. How biased is the data set by modern circumstances?

ii. How robust are the statistical models presented?

\subsubsection{Bias of Data Set}

We recognize two main mechanism that bias our data set: anthropogenic effects and sea level effects.

The bias associated with anthropogenic effects relates to the human impacts on modern landscapes and the natural processes acting on them. These impacts are so massive (Hooke, 2000; Wilkinson, 2005) that a new geological epoch, the Anthropocene, has been proposed to represent the period of human influence on climate and environment (Crutzen, 2006; Smith \& Zeder, 2013; Steffen et al., 2007; Zalasiewicz et al., 2008). Many of the human influences on natural environments impact sediment transport processes in fluvial systems. Plowing of agricultural fields (Montgomery, 2007) and loss of vegetative cover (Pimentel, 2006) increase soil erosion rates, while the total sediment load delivered to the world ocean by modern fluvial systems is reduced (Syvitski et al., 2005) by river management practices (Wang et al., 2011) and by dams, which both significantly alter water discharge and retain sediment by acting as sediment sinks (Syvitski et al., 2005). Irrigation and river diversion are human activities that reduce fluvial water discharge (Milliman \& Farnsworth, 2013). Some established suspended sediment load models address the anthropogenic impact on river catchments by including a parameter that quantifies this impact (Syvitski \& Milliman, 2007). Nevertheless, Métivier and Gaudemer (1999) demonstrated a remarkable correlation between the present-day sediment load estimates and sediment load estimates averaging $10^{6}$ year of sediment delivery by some very large Asian fluvial systems. This result indicates that the human impact on the sediment load delivered by these large Asian fluvial systems may still be attenuated by the significant buffering capacity of the associated alluvial systems. This interpretation suggests that the progradation rates associated with large fluvial systems may be more representative of geological progradation rates than those measured in smaller systems.

The bias associated with sea level effects relates to the modern sea level configuration. Extraction of water into glaciers and the current tectonic plate configuration results in the modern eustatic sea level being low in a deep-time geological context (Miller et al., 2005), while it is high in the context of the sea level oscillation characterizing the last 800,000 years (Hansen et al., 2013). High-amplitude sea level variations have contributed to erosive incision along modern coastlines (Blum \& Hattier-Womack, 2009), and the depositional patterns of modern deltaic systems are dominated by a rapidly rising global sea level over the last 6,000 years (Bird et al., 2010). Presently, global sea level rises approximately 1-2 mm/year on average (Douglas, 2001). These two factors combined, erosive incision and rising sea level, have produced a coastline dominated by far more estuarine environments than is typical in the stratigraphic record (Blum \& Hattier-Womack, 2009). Shelf-margin deltas are particularly underrepresented in modern environments. This fact means that the systems sampled in this study are not a uniform representation of deep-time geological delta deposits, at least not with respect to delta configuration and relative sea level change.

\subsubsection{Robustness of Models}

The robustness of the models depends on how representative the correlation between progradation rates and the catchment properties derived from modern systems is of ancient systems. Our confidence in the models is limited by the fact that they are based on a statistical correlation between parameters, which is not guided by a predefined model of physical processes. It is worth stressing that the parameters used in the correlations are particularly relevant to problems relating to fluvial discharge (Milliman \& Farnsworth, 2013). The following discussion is based on two assumptions: 
i. The progradation rates are proxies for sediment load delivered by the fluvial system.

ii. There is a causal relationship between the dependent and independent parameters of the models related to the physics of sediment transport phenomena.

If the second assumption is not satisfied, then the models are purely statistical, and their robustness depends entirely on the bias of our data set. In this case, we refer to the discussion in the preceding section.

If the two assumptions are satisfied, then we can discuss the formulas in terms of sediment transport phenomena. There are two principal sediment transport regimes that frame this discussion: the supply-limited and the capacity-limited sediment transport regimes (Bravo-Espinosa et al., 2003; Mosselman \& Le, 2016). The hydraulic properties of the flow determine the transport rate in capacity-limited systems, while sediment availability controls the sediment transport rate of supply-limited systems. Consequently, we expect catchment properties that relate to hydraulic properties to correlate with the sediment load transport rates of capacity-limited systems and catchment properties that quantify sediment availability to correlate with the sediment load transport rates of supply-limited systems. The wash load fraction of the sediment load is nearly always supply limited (Bravo-Espinosa et al., 2003; Mosselman \& Le, 2016; Nordin \& Beverage, 1965); the only exception is in transient mudflows. Generally, modern rivers are supply limited; however, the bed load can be capacity limited in some cases (Bravo-Espinosa et al., 2003; Mosselman \& Le, 2016). This distinction means that if delta progradation is driven by suspended sediment load transport rates, then we must interpret the formulas in terms of supply-limited sediment transport processes and that if progradation is driven by bed load transport rates, then we must discuss it in terms of capacity-limited sediment transport processes.

If progradation is driven by the suspended sediment load delivered to the coastline by the fluvial system, then we expect progradation rates to be correlated with estimates of the fluvial suspended sediment load. Fortunately, suspended sediment load is one of the catchment parameters available in our data set, and we can easily evaluate this hypothesis. Our analysis indicates that the suspended sediment load is only the second most important parameter in our formulas. Additionally, we emphasize that the most important parameter in our formulas, water discharge, is not one of the most significant parameters of the state-of-the-art suspended sediment load models (Syvitski \& Milliman, 2007). Most of the variability in the suspended sediment load of modern fluvial systems is attributed to variations in catchment area, relief and lithology and not to fluvial water discharge (Syvitski \& Milliman, 2007).

If, on the other hand, progradation rates are driven by bed load transport rates, then we can look to empirical bed load formulas (Bagnold, 1980; Meyer-Peter \& Müller, 1948; Schoklitsch, 1934) for insight into how capacity-limited sediment transport processes may relate to catchment properties. These formulas estimate bed load as a function of hydraulic parameters, such as water discharge, slope, flow depth, and channel width. It is clear from the empirical bed load formulas that water discharge is an important control on bed load flux; it not only is included directly in some of the equations but also is an important control on flow velocity and flow depth. This relation corresponds well with our finding that fluvial water discharge is the most important parameter in our data set for predicting progradation rates. On the other hand, we also find that adding the suspended sediment load of the system to our model improves its fit with the data, and we note that this is not a common parameter in empirical bed load formulas, although it is worth mentioning that there are bed-material load formulas (Colby, 1964) that do include a suspended sediment concentration factor.

\subsection{Application in Stratigraphic Analysis}

We measured progradation rates representing the growth of the subaerial sections of modern deltaic systems along parts of the coastline that are adjacent to fluvial entry points. These rates are not representative of parts of the coastline away from fluvial entry points where basinal processes are expected to be more pronounced, and in situ investigation is required to determine how the measured rates are expressed in the subaqueous part of the shoreline clinoform. We emphasize that the measured progradation rates are not representative of the progradation of the entire shoreline-subaqueous delta composite clinoforms or shelf-edge clinoforms (Patruno \& Helland-Hansen, 2018), which occur over much larger spatial and temporal scales than the morphological changes we have investigated.

We are interested in using what we know about the catchment of a depositional system to make first-order estimates about the volume of delta front deposits that we can expect to be generated over some duration 


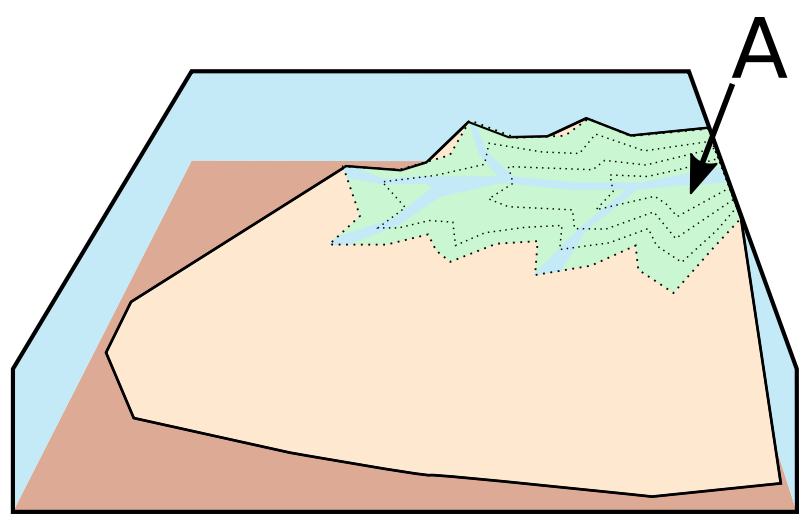

Figure 7. This model shows a delta lobe that has prograded at an average progradation rate $\hat{r}_{\text {pro }}$ over a duration $t$ to cover an area $A$. and the inverse statement, to derive some sense of how much time is needed to account for ancient three-dimensional deltaic sand bodies. These are mass balance problems (see section 2.1), where if we know the volume of sediment transported to the shoreline and the volume of sediment eroded away by marine processes, then we can quantify the volume of sediment retained at the shoreline (Burgess \& Hovius, 1998). Unfortunately, sediment supply is a difficult parameter to estimate in ancient sedimentary systems (Allen \& Allen, 2013; Turowski et al., 2010), particularly if one is interested in the coarser-grained bed load fraction that is a prominent contributor to shallow marine deltaic deposits. Bed load transport rates are difficult to quantify, even in modern systems (Emmett, 1981), and there is no bed load transport rate model that can be applied in deep-time stratigraphic analysis. We propose an alternative approach where we use delta progradation rates as a proxy for the amount of coarse-grained sediment transported to the coastline by the fluvial system. Explicitly, our hypothesis is that the area $A$ (Figure 7) covered by a prograding shoreline after a period $t$ in a basin without sediment remobilization by marine processes can be estimated as

$$
A=t \hat{r}_{\text {pro }}
$$

where $\hat{r}_{\text {pro }}$ is the average progradation rate and $A$ is the map view area enveloped by two shorelines (see Figure 7). This equation can also be used to produce a first-order estimate of the time represented by a mapped delta progradation event. Note that littoral processes remobilize and reorganize shoreline sedimentary deposits (see Figure 2) and that relative sea level change cause shoreline changes that are decoupled from sediment input.

To derive a representative average progradation rate, we recommend using equation (10) to derive the mean of a lognormal rate distribution and using 0.7 as its standard deviation (Figure 5). Using the formula for the average of a lognormal distribution (Stamey, 2008), we then have the estimated average rate given by

$$
\hat{r}_{\text {pro }}=10^{\left(\log \left(r_{\text {pro }}\right)+\frac{\sigma^{2}}{2}\right)}=10^{-2.3} Q^{0.59} Q_{s}^{0.34} .
$$

We emphasize that this average rate can be meaningful only when related to delta progradation or shoreline migrations recorded by deltaic deposits. Progradation rates are strongly timescale dependent (Sadler \& Jerolmack, 2014). This feature implies that it is not trivial to use rates produced by short-term observations in the analysis of long-term processes, particularly if the processes occur over different spatial and temporal scales (Aadland et al., 2018; Miall, 2014).

\section{Conclusion}

We quantified localized progradation rates that represent shoreline changes occurring directly adjacent to the fluvial entry points of modern deltaic systems. By comparing these rates with catchment and climate parameters, we were able to find formulas predicting the rates based on different catchment and climate parameters. The fundamental assumption of this analysis was that by extracting delta progradation rates from the part of the coastline that was closest to fluvial entry points, we were sampling progradation rates that were more reflective of fluvial processes than of basinal processes, and we used this assumption to justify a river-centric model of the progradation rates. We performed two simple preliminary tests that failed to reject this assumption.

We found that the model with water discharge and suspended sediment load as input parameters was the best compromise between predictability and simplicity. The model has an uncertainty of plus-or-minus 1 order of magnitude, and similar correlations are evident in other independent data sets. This formula has possible application in stratigraphic analysis, as it is feasible to constrain its parameters in ancient source-to-sink systems. We propose two uses of our data set within stratigraphic analysis: predicting the amount of progradation occurring in systems with known catchment properties and the inverse problem of estimating the duration represented by a mapped delta progradation. The applicability of the models 
Acknowledgments

The data analyzed in this study are publicly available as part of the supporting information of this publication. Interactive access to our classified shoreline change dataset is available at www.geo.uib.no/coaster. We are grateful for the editorial comments and critical review of Giovanni Coco, A. J. F. Hoitink, Helena van der Vegt, and anonymous reviewers. This research is funded by ARCEx partners and the Research Council of Norway (grant 228107). in stratigraphic analysis is limited by two major biases characterizing modern deltaic systems: the anthropogenic impact on modern catchments and modern sea level evolution. Finally, the rate compilation and the empirical model may be useful for researchers building analog and numerical models of deltaic systems as this model constrains the fluvial impact on the shoreline position of modern deltaic coastlines.

\section{References}

Aadland, T., \& Helland-Hansen, W. (2016). Global compilation of coastline change at river mouths. EGU General Assembly Conference Abstracts (Vol. 18, 3915 pp.). Vienna, Austria: EGU.

Aadland, T., Sadler, P., \& Helland-Hansen, W. (2018). Geometric interpretation of time-scale dependent sedimentation rates. Sedimentary Geology, 371, 32-40. https://doi.org/10.1016/j.sedgeo.2018.04.003

Ager, D. V. (1993). The nature of the stratigraphical record. 551.7 AGE.

Allen, P. A., \& Allen, J. R. (2013). Basin analysis: Principles and application to petroleum play assessment. Hoboken, NJ: John Wiley. Archiving, Validation and Interpretation of Satellite Oceanographic Data (2009). The altimeter products were produced and distributed by AVISO+ (https://www.aviso.altimetry.fr/), as part of the SSALTO ground processing segment. https://www.aviso.altimetry.fr/ en/data/products/windwave-products/mswhmwind.html, online; accessed 23 February 2017.

Ashton, A. D., \& Giosan, L. (2011). Wave-angle control of delta evolution. Geophysical Research Letters, 38, L13405. https://doi.org/10.1029/ 2011GL047630

Ashton, A. D., \& Murray, A. B. (2006). High-angle wave instability and emergent shoreline shapes: 1. Modeling of sand waves, flying spits, and capes. Journal of Geophysical Research, 111, F04011. https://doi.org/10.1029/2005JF000422

Bagnold, R. (1980). An empirical correlation of bedload transport rates in flumes and natural rivers. Proceedings of the Royal Society of London A, 372(1751), 453-473.

Bahgat, M. (2018). Optimum use of dredged materials for sustainable shoreline management in Nile delta. Water Science, 32, 115-128.

Berglund, M. (2004). Holocene shore displacement and chronology in Ångermanland, eastern Sweden, the Scandinavian glacio-isostatic uplift centre. Boreas, 33(1), 48-60.

Bird, M. I., Austin, W. E., Wurster, C. M., Fifield, L. K., Mojtahid, M., \& Sargeant, C. (2010). Punctuated eustatic sea-level rise in the early mid-Holocene. Geology, 38(9), 803. https://doi.org/10.1130/G31066.1

Blum, M. D., \& Hattier-Womack, J. (2009). Climate change, sea-level change, and fluvial sediment supply to deepwater depositional systems. https://doi.org/10.2110/sepmsp.092

Blum, M. D., \& Roberts, H. H. (2009). Drowning of the mississippi delta due to insufficient sediment supply and global sea-level rise. Nature Geoscience, 2(7), 488.

Bravo-Espinosa, M., Osterkamp, W., \& Lopes, V. L. (2003). Bedload transport in alluvial channels. Journal of Hydraulic Engineering, 129(10), 783-795.

Burgess, P., \& Hovius, N. (1998). Rates of delta progradation during highstands: Consequences for timing of deposition in deep-marine systems. Journal of the Geological Society, 155(2), 217-222. https://doi.org/10.1144/gsjgs.155.2.0217

Caldwell, R., Edmonds, D., Baumgardner, S., Paola, C., Roy, S., \& Nienhuis, J. (2017). Controls on delta formation, area, and topset slope: New predictive relationships developed using a global delta dataset. AGU Fall Meeting Abstracts.

Charvin, K., Hampson, G. J., Gallagher, K. L., Storms, J. E., \& Labourdette, R. (2011). Characterization of controls on high-resolution stratigraphic architecture in wave-dominated shoreface-shelf parasequences using inverse numerical modeling. Journal of Sedimentary Research, 81(8), 562-578.

Colby, B. R. (1964). Practical computations of bed-material discharge. Journal of the Hydraulics Division, 90(2), $217-246$.

Constantine, J. A., Dunne, T., Ahmed, J., Legleiter, C., \& Lazarus, E. D. (2014). Sediment supply as a driver of river meandering and floodplain evolution in the Amazon basin. Nature Geoscience, 7(12), 899-903.

Climate Prediction Center (2018). CPC global temperature data provided by the NOAA/OAR/ESRL PSD, Boulder, Colorado, USA. Retrieved from https://www.esrl.noaa.gov/psd/, accessed: 2018-04-06

Crutzen, P. J. (2006). The "Anthropocene" (pp. 13-18). Berlin, Heidelberg: Springer Berlin Heidelberg. https://doi.org/10.1007/3-54026590-2_3

d'Agostino, R. B. (1971). An omnibus test of normality for moderate and large size samples. Biometrika, 58(2), 341-348.

Day, J. W., Martin, J. F., Cardoch, L., \& Templet, P. H. (1997). System functioning as a basis for sustainable management of deltaic ecosystems. Coastal Management, 25(2), 115-153.

Dietz, R. S. (1963). Wave-base, marine profile of equilibrium, and wave-built terraces: A critical appraisal. Geological Society of America Bulletin, 74(8), 971-990.

Donchyts, G., Baart, F., Winsemius, H., Gorelick, N., Kwadijk, J., \& van de Giesen, N. (2016). Earth's surface water change over the past 30 years. Nature Climate Change, 6(9), 810-813.

Douglas, B. C. (2001). Sea level change in the era of the recording tide gauge. International Geophysics, 75, 37-64. Elsevier.

Edmonds, D., Caldwell, R., Baumgardner, S., Paola, C., Roy, S., Nelson, A., \& Nienhuis, J. (2017). A global analysis of human habitation on river deltas, EGU General Assembly Conference abstracts (Vol. 19, pp. 10832). Vienna, Austria: EGU.

Edmonds, D. A., \& Slingerland, R. L. (2007). Mechanics of river mouth bar formation: Implications for the morphodynamics of delta distributary networks. Journal of Geophysical Research, 112, F02034. https://doi.org/10.1029/2006JF000574

Eide, C. H., Klausen, T. G., Katkov, D., Suslova, A. A., \& Helland-Hansen, W. (2017). Linking an early triassic delta to antecedent topography: Source-to-sink study of the southwestern Barents Sea margin. GSA Bulletin.

Emmett, W. W. (1981). Measurement of bedload in rivers. Erosion and Sediment Transport Measurement. Proceedings of the Florence Symposium, June 1981 (no. 133, pp. 3-16). IAHS Publ.

GRACE Tellus (2004). Glacial isostatic adjustment (GIA). Retrieved from http://grace.jpl.nasa.gov, online; accessed 14 Mars 2017.

Galloway, W. E. (1975). Process framework for describing the morphologic and stratigraphic evolution of deltaic depositional systems.

Geleynse, N., Storms, J., Stive, M., Jagers, H., \& Walstra, D. (2010). Modeling of a mixed-load fluvio-deltaic system. Geophysical Research Letters, 37, L05402. https://doi.org/10.1029/2009GL042000

Gorelick, N., Hancher, M., Dixon, M., Ilyushchenko, S., Thau, D., \& Moore, R. (2017). Google Earth Engine: Planetary-scale geospatial analysis for everyone. Remote Sensing of Environment, 202, 18-27. https://doi.org/10.1016/j.rse.2017.06.031 
Ham, D. G., \& Church, M. (2000). Bed-material transport estimated from channel morphodynamics: Chilliwack River, British Columbia. Earth Surface Processes and Landforms, 25(10), 1123-1142.

Hansen, J., Sato, M., Russell, G., \& Kharecha, P. (2013). Climate sensitivity, sea level and atmospheric carbon dioxide. Philosophical Transactions of the Royal Society of London A: Mathematical, Physical and Engineering Sciences, 371(2001). https://doi.org/10.1098/rsta.2012.0294 Helland-Hansen, W., \& Hampson, G. (2009). Trajectory analysis: Concepts and applications. Basin Research, 21(5), 454-483.

Helland-Hansen, W., \& Martinsen, O. J. (1996). Shoreline trajectories and sequences: Description of variable depositional-dip scenarios. Journal of Sedimentary Research, 66(4), 1170-1170.

Helland-Hansen, W., Sømme, T. O., Martinsen, O. J., Lunt, I., \& Thurmond, J. (2016). Deciphering Earth's natural hourglasses: Perspectives on source-to-sink analysis. Journal of Sedimentary Research, 86(9), 1008-1033.

Hooke, R. L. (2000). On the history of humans as geomorphic agents. Geology, 28(9), 843. https://doi.org/10.1130/0091-7613(2000)28< 843:OTHOHA > 2.0.CO;2

Hori, K., Saito, Y., Zhao, Q., Cheng, X., Wang, P., Sato, Y., \& Li, C. (2001). Sedimentary facies and holocene progradation rates of the Changjiang (Yangtze) Delta, China. Geomorphology, 41(2-3), 233-248.

Ibàñez, C., Canicio, A., Day, J. W., \& Curcó, A. (1997). Morphologic development, relative sea level rise and sustainable management of water and sediment in the Ebre delta, Spain. Journal of Coastal Conservation, 3(1), 191-202.

Islam, M. R., Begum, S. F., Yamaguchi, Y., \& Ogawa, K. (1999). The Ganges and Brahmaputra Rivers in Bangladesh: Basin denudation and sedimentation. Hydrological Processes, 13(17), 2907-2923.

Jakobsson, M., Mayer, L., Coakley, B., Dowdeswell, J. A., Forbes, S., Fridman, B., et al. (2012). The International Bathymetric Chart of the Arctic Ocean (IBCAO) version 3.0. Geophysical Research Letters, 39, L12609. https://doi.org/10.1029/2012GL052219

Jones, E., Oliphant, T., \& Peterson, P. (2014). \{SciPy\}: open source scientific tools for \{Python\}.

Kim, W., Mohrig, D., Twilley, R., Paola, C., \& Parker, G. (2009). Is it feasible to build new land in the Mississippi River delta? EOS, Transactions American Geophysical Union, 90(42), 373-374.

Kim, W., Paola, C., Swenson, J. B., \& Voller, V. R. (2006). Shoreline response to autogenic processes of sediment storage and release in the fluvial system. Journal of Geophysical Research, 111, F04013. https://doi.org/10.1029/2006JF000470

Knutson, T. R., McBride, J. L., Chan, J., Emanuel, K., Holland, G., Landsea, C., et al. (2010). Tropical cyclones and climate change. Nature Geoscience, 3(3), 157.

Komar, P. D. (1971). The mechanics of sand transport on beaches. Journal of Geophysical Research, 76(3), 713-721.

Kreemer, C., Haines, J., Holt, W. E., Blewitt, G., \& Lavallee, D. (2000). On the determination of a global strain rate model. Earth, Planets and Space, 52(10), 765-770.

Kuenzer, C., \& Renaud, F. G. (2012). Climate and environmental change in river deltas globally: Expected impacts, resilience, and adaptation, The Mekong Delta System pp. 7-46). Netherlands: Springer.

Lane, E. W. (1954). Importance of fluvial morphology in hydraulic engineering. Denver, CO: U.S. Department of the Interior, Bureau of Reclamation, Commissioner's Office.

Luijendijk, A., Hagenaars, G., Ranasinghe, R., Baart, F., Donchyts, G., \& Aarnikhof, S. (2018). The state of the world's beaches. Scientific Reports, 8(6641), 1-11.

Mahon, R. C., Shaw, J. B., Barnhart, K. R., Hobley, D. E. J., \& McElroy, B. (2015). Quantifying the stratigraphic completeness of delta shoreline trajectories. Journal of Geophysical Research: Earth Surface, 120, 799-817. https://doi.org/10.1002/2014JF003298

Martin, Y., \& Church, M. (1995). Bed-material transport estimated from channel surveys: Vedder River, British Columbia. Earth Surface Processes and Landforms, 20(4), 347-361.

Mason, T., \& Coates, T. (2001). Sediment transport processes on mixed beaches: A review for shoreline management. Journal of Coastal Research, 17, 645-657.

McGranahan, G., Balk, D., \& Anderson, B. (2007). The rising tide: Assessing the risks of climate change and human settlements in low elevation coastal zones. Environment and Urbanization, 19(1), 17-37.

Métivier, F., \& Gaudemer, Y. (1999). Stability of output fluxes of large rivers in South and East Asia during the last 2 million years: Implications on floodplain processes. Basin Research, 11(4), 293-303.

Métivier, F., Meunier, P., Moreira, M., Crave, A., Chaduteau, C., Ye, B., \& Liu, G. (2004). Transport dynamics and morphology of a high mountain stream during the peak flow season: The ürümqi River (Chinese Tian Shan), River flow (Vol. 1, pp. 761-777). Leiden, London: A.A. Balkema.

Meunier, P., Métivier, F., Lajeunesse, E., Meriaux, A., \& Faure, J. (2006). Flow pattern and sediment transport in a braided river: The "Torrent de St. Pierre" (French Alps). Journal of Hydrology, 330(3-4), 496-505.

Meyer-Peter, E., \& Müller, R. (1948). Formulas for bed-load transport. in: IAHSR 2nd meeting, Stockholm, appendix 2, IAHR.

Miall, A. D. (2014). Updating Uniformitarianism: Stratigraphy as just a set of "Frozen Accidents" (Vol. 404, pp. SP404-4). London: Geological Society, London, Special Publications.

Miller, K. G., Kominz, M. A., Browning, J. V., Wright, J. D., Mountain, G. S., Katz, M. E., et al. (2005). The Phanerozoic record of global sea-level change. Science, 310(5752), 1293-1298. https://doi.org/10.1126/science.1116412

Milliman, J. D., \& Farnsworth, K. L. (2013). River discharge to the Coastal Ocean: A global synthesis. Cambridge, UK: Cambridge University Press.

Milliman, J. D., \& Syvitski, J. P. (1992). Geomorphic/tectonic control of sediment discharge to the ocean: The importance of small mountainous rivers. The Journal of Geology, 100(5), 525-544.

Montgomery, D. R. (2007). Soil erosion and agricultural sustainability. Proceedings of the National Academy of Sciences, 104(33), 13,268-13,272. https://doi.org/10.1073/pnas.0611508104

Mosselman, E., \& Le, T. B. (2016). Five common mistakes in fluvial morphodynamic modeling. Advances in Water Resources, 93, 15-20.

Mulder, T., \& Syvitski, J. P. (1995). Turbidity currents generated at river mouths during exceptional discharges to the world oceans. The Journal of Geology, 103(3), 285-299.

Nanson, G. C. (1974). Bedload and suspended-load transport in a small, steep, mountain stream. American Journal of Science, 274(5), 471-486.

National Oceanic and Atmospheric Administration (2016). Digital elevation model of Myrtle Beach, South Carolina, courtesy of the National Oceanic and Atmospheric Administration. https://www.ngdc.noaa.gov/mgg/coastal/, accessed: 2016-12-20.

Nordin, C. F., \& Beverage, J. P. (1965). Sediment transport in the Rio Grande (pp. 462-463). New Mexico: US Government Printing Office. OpenStreetMap Contributors (2017). Planet dump. retrieved from https://planet.osm.org, https://www.openstreetmap.org

Paola, C., Straub, K., Mohrig, D., \& Reinhardt, L. (2009). The "unreasonable effectiveness" of stratigraphic and geomorphic experiments. Earth-Science Reviews, 97(1-4), 1-43. 
Paola, C., Twilley, R. R., Edmonds, D. A., Kim, W., Mohrig, D., Parker, G., et al. (2011). Natural processes in delta restoration: Application to the Mississippi delta. Annual Review of Marine Science, 3, 67-91.

Patruno, S., Hampson, G. J., Jackson, C. A.-L., \& Whipp, P. S. (2015). Quantitative progradation dynamics and stratigraphic architecture of ancient shallow-marine clinoform sets: A new method and its application to the upper Jurassic Sognefjord formation, Troll field, offshore Norway. Basin Research, 27(4), 412-452.

Patruno, S., \& Helland-Hansen, W. (2018). Clinoform systems: Review and dynamic classification scheme for shorelines, subaqueous deltas, shelf edges and continental margins. Earth-Science Reviews, 185, 202-233.

Pekel, J.-F., Cottam, A., Gorelick, N., \& Belward, A. S. (2016). High-resolution mapping of global surface water and its long-term changes Nature, 540(7633), 418-422.

Pelpola, C. P., \& Hickin, E. J. (2004). Long-term bed load transport rate based on aerial-photo and ground penetrating radar surveys of fan-delta growth, Coast Mountains, British Columbia. Geomorphology, 57(3), 169-181.

Peltier, W. (2004). Global glacial isostasy and the surface of the Ice-Age Earth: The ICE-5G (VM2) model and GRACE. Annual Review of Earth and Planetary Sciences, 32, 111-149.

Pilkey, O. H., Young, R. S., Rîggs, S. R., Smith, A. S., Wu, H., \& Pilkey, W. D. (1993). The concept of shoreface profile of equilibrium: A critical review. Journal of Coastal Research, 9, 255-278.

Pimentel, D. (2006). Soil erosion: A food and environmental threat. Environment, Development and Sustainability, 8(1), 119-137. https://doi.org/10.1007/s10668-005-1262-8

Reitz, M. D., Jerolmack, D. J., \& Swenson, J. B. (2010). Flooding and flow path selection on alluvial fans and deltas. Geophysical Research Letters, 37, L06401. https://doi.org/10.1029/2009GL041985

Ryer, T. A. (1977). Patterns of cretaceous shallow-marine sedimentation, Coalville and Rockport areas, Utah. Geological Society of America Bulletin, 88(2), 177-188.

Sadler, P. M., \& Jerolmack, D. J. (2014). Scaling laws for aggradation, denudation and progradation rates: The case for time-scale invariance at sediment sources and sinks. Geological Society, London, Special Publications, 404, SP404-7.

Schoklitsch, A. (1934). Der geschiebetrieb und die geschiebefracht. Wasserkraft Wasserwirtschaft, 4, 1-7.

Slott, J. M., Murray, A. B., Ashton, A. D., \& Crowley, T. J. (2006). Coastline responses to changing storm patterns. Geophysical Research Letters, 33, L18404. https://doi.org/10.1029/2006GL027445

Smith, B. D., \& Zeder, M. A. (2013). The onset of the Anthropocene. Anthropocene, 4, 8-13.

Sømme, T. O., Helland-Hansen, W., Martinsen, O. J., \& Thurmond, J. B. (2009). Relationships between morphological and sedimentological parameters in source-to-sink systems: A basis for predicting semi-quantitative characteristics in subsurface systems. Basin Research, 21(4), 361-387.

Stamey, J. (2008). Modern mathematical statistics with applications. New York: Springer-Verlag.

Steffen, W., Crutzen, P. J., \& McNeill, J. R. (2007). The anthropocene: Are humans now overwhelming the great forces of nature. AMBIO: A Journal of the Human Environment, 36(8), 614-621.

Straub, K. M., Li, Q., \& Benson, W. M. (2015). Influence of sediment cohesion on deltaic shoreline dynamics and bulk sediment retention: A laboratory study. Geophysical Research Letters, 42, 9808-9815. https://doi.org/10.1002/2015GL066131

Straub, K. M., Paola, C., Kim, W., \& Sheets, B. (2013). Experimental investigation of sediment-dominated vs. tectonics-dominated sediment transport systems in subsiding basins. Journal of Sedimentary Research, 83, 1162-1180.

Struijk, A., \& Green, R. (1991). The Brent Field, Block 211/29, UK North Sea. Geological Society, London, Memoirs, 14(1), 63-72.

Swenson, J. B., Paola, C., Pratson, L., Voller, V. R., \& Murray, A. B. (2005). Fluvial and marine controls on combined subaerial and subaqueous delta progradation: Morphodynamic modeling of compound-clinoform development. Journal of Geophysical Research, 110, F02013. https://doi.org/10.1029/2004JF000265

Syvitski, J. P., Kettner, A. J., Overeem, I., Hutton, E. W., Hannon, M. T., Brakenridge, G. R., et al. (2009). Sinking deltas due to human activities. Nature Geoscience, 2(10), 681.

Syvitski, J. P. M., \& Milliman, J. D. (2007). Geology, geography and humans battle for dominance over the delivery of fluvial sediment to the coastal ocean. The Journal of Geology, 115, 1-19.

Syvitski, J. P., Peckham, S. D., Hilberman, R., \& Mulder, T. (2003). Predicting the terrestrial flux of sediment to the global ocean: A planetary perspective. Sedimentary Geology, 162(1-2), 5-24.

Syvitski, J. P. M., Vörösmarty, C. J., Kettner, A. J., \& Green, P. (2005). Impact of humans on the flux of terrestrial sediment to the global coastal ocean. Science, 308(5720), 376-380. https://doi.org/10.1126/science.1109454

Szabo, S., Brondizio, E., Renaud, F. G., Hetrick, S., Nicholls, R. J., Matthews, Z., et al. (2016). Population dynamics, delta vulnerability and environmental change: Comparison of the Mekong, Ganges-Brahmaputra and Amazon delta regions. Sustainability Science, 11(4), 539-554.

Ta, T. K. O., Nguyen, V. L., Tateishi, M., Kobayashi, I., Saito, Y., \& Nakamura, T. (2002). Sediment facies and late holocene progradation of the Mekong River delta in Bentre Province, southern Vietnam: An example of evolution from a tide-dominated to a tide-and wave-dominated delta. Sedimentary Geology, 152(3-4), 313-325.

Turowski, J. M., Rickenmann, D., \& Dadson, S. J. (2010). The partitioning of the total sediment load of a river into suspended load and bedload: A review of empirical data. Sedimentology, 57(4), 1126-1146.

U.S. Geological Survey (2016). Landsat 4, 5, 7 and 8 thematic mapper derived top-of-atmosphere corrected reflectance images courtesy of the U.S. Geological Survey. http://earthexplorer.usgs.gov, accessed: 2016-08-08

U.S. Geological Survey-Global 30 Arc-Second Elevation (2016). Global 30 arc-second elevation model courtesy of the U.S. Geological Survey. http://earthexplorer.usgs.gov, accessed: 2016-08-08.

Van Wagoner, J., Posamentier, H., Mitchum, R., Vail, P., Sarg, J., Loutit, T., \& Hardenbol, J. (1988). An overview of the fundamentals of sequence stratigraphy and key definitions.

Wahr, J., \& Zhong, S. (2012). Computations of the viscoelastic response of a 3-D compressible Earth to surface loading: An application to glacial isostatic adjustment in Antarctica and Canada. Geophysical Journal International, 192(2), 557-572.

Wang, H., Saito, Y., Zhang, Y., Bi, N., Sun, X., \& Yang, Z. (2011). Recent changes of sediment flux to the western Pacific Ocean from major rivers in East and Southeast Asia. Earth-Science Reviews, 108(1-2), 80-100.

Webster, P. J., Holland, G. J., Curry, J. A., \& Chang, H.-R. (2005). Changes in tropical cyclone number, duration, and intensity in a warming environment. Science, 309(5742), 1844-1846.

Wilkinson, B. H. (2005). Humans as geologic agents: A deep-time perspective. Geology, 33(3), 161. https://doi.org/10.1130/G21108.1

Williams, G. P., \& Rosgen, D. L. (1989). Measured total sediment loads (suspended loads and bedloads) for 93 United States streams. Citeseer. 
$\mathrm{Xu}, \mathrm{H}$. (2006). Modification of normalised difference water index (NDWI) to enhance open water features in remotely sensed imagery. International Journal of Remote Sensing, 27(14), 3025-3033. https://doi.org/10.1080/01431160600589179

Zalasiewicz, J., Williams, M., Smith, A., Barry, T. L., Coe, A. L., Bown, P. R., et al. (2008). Are we now living in the Anthropocene? Gsa Today, 18(2), 4.

Zhu, Z., \& Woodcock, C. E. (2012). Object-based cloud and cloud shadow detection in Landsat imagery. Remote Sensing of Environment, 118, 83-94. https://doi.org/10.1016/j.rse.2011.10.028 